\title{
AUSREM
}

\section{AuSREM: Australian Seismological Reference Model}

\author{
B.L.N. Kennett and M. Salmon \\ Research School of Earth Sciences, The Australian National University, Canberra, ACT 0200, Australia
}

\begin{abstract}
Although Australia has been the subject of a wide range of seismological studies, these have concentrated on specific features of the continent at crustal scales and on the broad scale features in the mantle. The Australian Seismological Reference Model (AuSREM) is designed to bring together the existing information, and provide a synthesis in the form of a 3-D model that can provide the basis for future refinement from more detailed studies. The model is grid based with a 0.5 degree sampling in latitude and longitude and is designed to be fully interpolable, so that properties can be extracted at any point. The crustal component makes use of prior compilations of sediment thicknesses, with cross checks against recent reflection profiling, and provides $\mathrm{P}$ and $\mathrm{S}$ wavespeed distributions through the crust. The primary information for $\mathrm{P}$ wavespeed comes from refraction profiles, for $\mathrm{S}$ wavespeed from receiver function studies, and we are able to use the results of ambient noise tomography to link the point observations into national coverage. Density values are derived using results from gravity interpretations. AuSREM is able to build on a new map of depth to Moho, which has been created using all available information including Moho picks from over 10,000 km of full crustal profiling across the continent (Kennett et al., 2011). In the upper mantle the primary source of information comes from seismic surface wave tomography and a representative model has been developed to capture the features of a range of studies. Body wave studies and regional tomography provide useful constraints on the relation between $\mathrm{P}$ and $\mathrm{S}$ wavespeeds. The mantle model extends beyond the continent and so covers a larger area than for the crust. Below $350 \mathrm{~km}$ and in the surrounding area AuSREM is linked to the S40RTS model (Ritsema et al., 2011). Potential applications of the AuSREM model come through the delineation of major structural features in the crust and mantle, and consequent improvements in, e.g., earthquake location within the continent and at the nearby plate boundaries.
\end{abstract}

Accepted for Publication in: Australian Journal of Earth Sciences 


\section{Introduction}

The Australian Seismological Reference Model (AuSREM) is designed to capture the wide range of seismological information generated over the last few decades on the structure beneath the Australian region exploiting both natural and man-made sources. The objective is to provide a representation of the 3-D structure beneath Australia and its environs in a form that summarises existing knowledge and provides a basis for future refinement from more detailed studies. Potential applications of the model include improved earthquake locations, both within Australia and at the immediate plate boundaries by using better representations of crustal and mantle structure and delineation of major structural features. The reference model has been built using Australian specific information of varying vintage and quality. The aim is not to attempt to produce a definitive model, but rather to capture the major features of the continental structure in a way that will allow testing against future results.

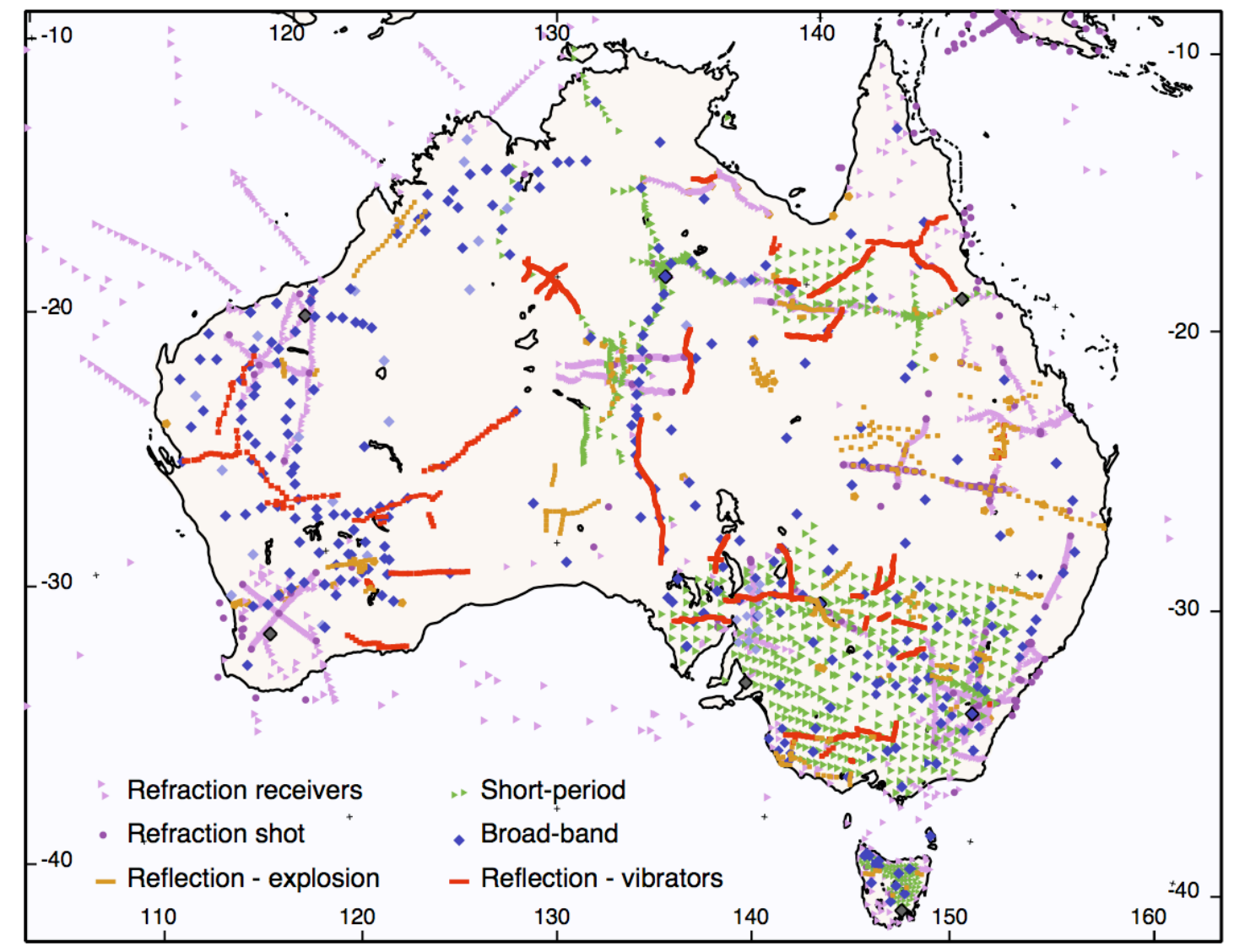

Figure 1 --Locations of seismological studies across Australia to mid 2012 showing the locations of active studies: refraction surveys (purple) and shotpoints (circles), reflection lines (orange - explosive sources, red - vibrator sources) and passive studies: broad-band recording stations (diamonds) and short-period stations (triangles), as indicated on the key.

As can be seen from Figure 1, there is good general coverage of the Australian continent, particularly for passive seismic studies using broad-band or short-period recording at portable seismic stations. Such stations can be used to exploit recordings of natural events and the record of continuous ground motion. Techniques using active sources are more constrained by logistics, and although coverage is good at the continental scale, there a number of prominent holes. Access to some areas remains problematic. 


\section{Nature of Model}

The AuSREM model is grid based with 0.5 degree sampling in both latitude and longitude. At each grid point the properties beneath are defined in terms of the depths of major boundaries such as the base of the sediments and the Moho, and the seismic P and S wavespeeds and density as a function of depth. The model is designed for interpolation, so that properties can be extracted at any point. In a number of the subsequent figures we employ $0.5 x 0.5$ degree pixels so that the effective resolution can be judged, but the AUSREM model itself is not cellular.

For the crust, much of the control is on the $\mathrm{P}$ wavespeed, and then $\mathrm{S}$ wavespeeds and density have to be inferred using other information. We have built up a database of well constrained results using different types of seismic data and gravity interpretations to aid with the extraction of the secondary variables.

For the mantle, in contrast, the strongest constraint is on the $\mathrm{S}$ wavespeed distribution. We employ conversion relations derived from studies of refracted arrivals in the mantle (Kaiho \& Kennett, 2000) to provide a laterally varying conversion scheme for conversion to $\mathrm{P}$ wavespeed. Construction of the density distribution from the $S$ wavespeed takes account of the likely compositional variation, particularly for the cratons where density is comparatively low in the upper mantle.

The AuSREM crustal grid extends from $110^{\circ} \mathrm{E}$ to $160^{\circ} \mathrm{E}$ and from $10^{\circ} \mathrm{S}$ to $45^{\circ} \mathrm{S}$. In the crust the representation is via a 5 -layered structure at each point (see Table 1), with linear gradients in properties between the boundaries. This simple form provides considerable flexibility and has been widely used in seismic receiver function studies (e.g. Shibutani et al., 1996; van der Hilst et al, 1998; Clitheroe et al, 2000). Summary values are extracted from the model across the entire grid at $5 \mathrm{~km}$ depth intervals.

Table 1. - AuSREM crustal representation

\begin{tabular}{|l|l|l|l|l|}
\hline Layer & $h \mathrm{~km}$ & $V_{p} \mathrm{~km} / \mathrm{s}$ & $V_{s} \mathrm{~km} / \mathrm{s}$ & $V_{p} / V_{s}$ \\
\hline Sediments & $0.0-2.0$ & $1.0-4.3$ & $0.5-1.5$ & $2.00-3.00$ \\
\hline Basement & $0.0-3.0$ & $2.8-5.4$ & $1.7-2.7$ & $1.65-2.00$ \\
\hline Upper Crust & $5.0-20.0$ & $4.8-6.8$ & $2.9-3.9$ & $1.65-1.80$ \\
\hline Middle Crust & $5.0-20.0$ & $5.6-7.5$ & $3.4-4.4$ & $1.65-1.80$ \\
\hline Lower Crust & $0.0-15.0$ & $6.1-7.8$ & $3.7-4.7$ & $1.65-1.80$ \\
\hline
\end{tabular}

In the mantle the grid is represented at $25 \mathrm{~km}$ intervals from $50 \mathrm{~km}$ depth to $350 \mathrm{~km}$ depth with a grid over a slightly larger region than for the crust from $105^{\circ} \mathrm{E}$ to $180^{\circ} \mathrm{E}$ and from $0^{\circ} \mathrm{S}$ to $50^{\circ} \mathrm{S}$. At greater depth and in surrounding areas, the AuSREM model is linked to S40RTS (Ritsema et al., 2011), which builds on global observations of seismic surface waves and longperiod body waves.

A slice at $50 \mathrm{~km}$ depth cuts the Moho in a few places across the continent (Kennett et al., 2011). Crustal influences on estimates of mantle structure are rather strong at this depth, and so we use information from refraction and receiver function studies as the primary control at this depth. 


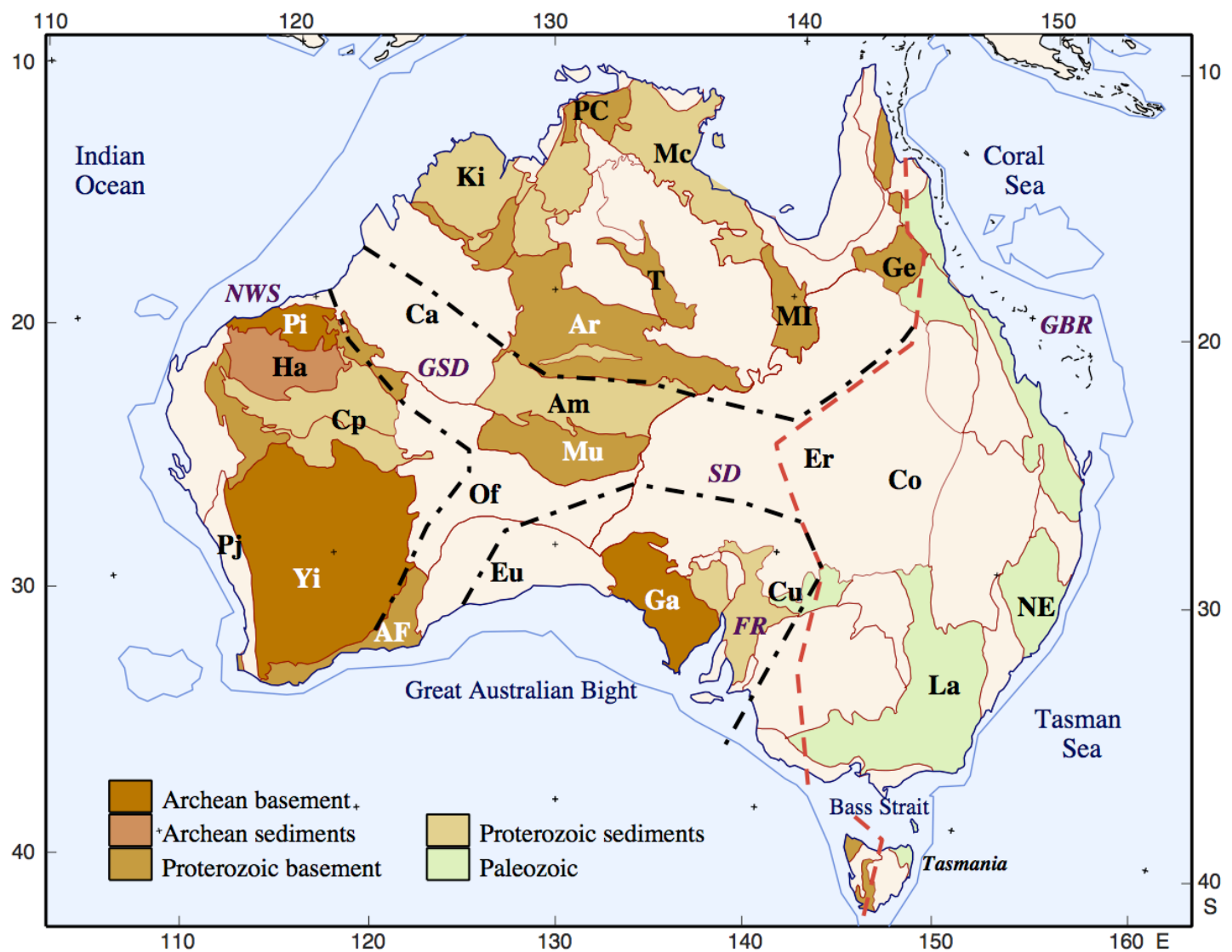

Figure 2 -- Simplified representation of the main tectonic features of Australia. The outlines of the major cratons are marked by chain-dotted lines. The approximate location of the boundary between Precambrian outcrop in western and central Australia and the Phanerozoic east (the "Tasman line") based on the reinterpretation by Direen \& Crawford (2003) is indicated by a red dashed line. Key to marked features: AF - Albany-Fraser Orogen, Ar - Arunta Block, Am - Amadeus Basin, Ca - Canning Basin, Co - Cooper Basin, Cp - Capricorn Orogen, Cu - Curnamona Craton, Er - Eromanga Basin, Eu - Eucla Basin, Ga - Gawler Craton, Ge Georgetown Inlier, Ha - Hamersley Basin, Ki - Kimberley Block, La - Lachlan Orogen, Mc - MacArthur Basin, MI - Mt Isa Inlier, Mu - Musgrave Orogen, NE - New England Orogen, Of - Officer Basin, PC - Pine Creek Inlier, Pi - Pilbara Craton, Pj - Pinjarra Orogen, T - Tennant Creek Inlier, Yi - Yilgarn Craton; SD Simpson Desert, GSD - Great Sandy Desert, GBR - Great Barrier Reef, NWS - North West Shelf.

\section{Nature of Data Sources}

The extensive application of seismological methods, using natural and man-made sources has covered most of the major tectonic units (Figure 2). The methods are not inhibited by surface cover, though strong sedimentary reverberations can sometimes mask important information from depth. AuSREM is built entirely from Australian specific data, and we have not attempted to invoke analogies with other areas across the globe as in, e.g., CRUST 5.1 (Mooney et al., 1998), and its successors. Detailed discussion of the data sources and the technical details of the construction of the crustal and mantle components are provided in the companion papers (Salmon et al., 2012; Kennett et al., 2012).

A number of major refraction experiments were carried out from the 1960s into the 1980s and provide an important control on seismic wavespeeds across the continent. There has been little such work since, except some off-shore/on-shore experiments mostly in Western Australia. Reflection studies of the whole crust have grown from short experimental spreads 
in the 1960s to large-scale transects. A historical overview and extensive bibliography of the full range of active seismic experiments up to 2006 is given by Finlayson (2010).

A nearly $2000 \mathrm{~km}$ long reflection transect with $20 \mathrm{~s}$ recording was built up across southern Queensland in the 1980s using explosive sources. Explosive sources continued to be used until 1997, when they were replaced with arrays of powerful vibrator sources. Since 2004 there has been a major national investment in seismic reflection work funded through investment from Geoscience Australia, State and Territory geological surveys and, since 2007, the AuScope infrastructure initiative. Over $12,000 \mathrm{~km}$ of full crustal reflection profiles have been acquired with recording to $20 \mathrm{~s}$ or more. This very large effort has provided new insights into crustal structure, architecture and evolution in a number of parts of the continent. The dense sampling provided by the reflection transects has been of considerable value in mapping the character and geometry of the Moho across the continent (Kennett et al., 2011).

The configuration of earthquake belts around the margins of Australia provides a wealth of events at suitable distances to be used as probes into the seismic structure of the upper mantle. Until recently there have only been a few permanent high-fidelity seismic stations on the continent. Much data collection has therefore been acquired through extensive deployments of portable broadband stations for periods of a few months at each site. This approach was pioneered with the SKIPPY experiment (van der Hilst et al., 1994) where a group of stations were progressively moved across the continent in a sequence of deployments. This style of experiments has inspired many similar efforts world-wide (such as major deployments in South Africa, James et al., 2001, and the US Array, http://www.usarray.org). The expansion of the Australian tsunami warning system since 2004 has meant that there is now an improved national network of permanent broadband stations that provide an important supplement to the shorter duration portable deployments,

The combination of a long duration of recording at the permanent stations and the broad spatial coverage of the portable stations provides an excellent resource for studies of the lithosphere. A wide range of techniques, which exploit different aspects of seismograms, can be used to gain information on the 3-D structure in the crust and mantle.

A sequence of dense deployments of 3-component shorter-period instruments across the southeastern corner of the continent since 1999 has been brought together in the WOMBAT project (Rawlinson et al., 2011). These dense deployments provide detailed information on crustal and mantle structure.

\section{Passive seismic}

Many different techniques have been employed to exploit the wealth of information available from the extensive coverage of the continent using portable seismic instruments. Most of the studies exploit seismograms from earthquakes, either in the regional belts of events to the north and east of Australia, or from more distant sources. A new approach, which is of particular value for crustal studies, exploits the ambient noise field, by working with the stacked correlation of records at pairs of stations. The result is equivalent to having a virtual source at one of the stations with a receiver at the other. The surface wave energy is the most prominent feature of the stacked correlation and has been exploited by Saygin \& Kennett $(2010,2012)$ to map the variations in $S$ wavespeeds in the upper and middle crust. 
Large amplitude surface waves can be used in a tomographic inversion to determine the 3-D variations in shear wavespeed in the mantle. These relatively late arrivals in the seismogram travel nearly horizontally from regional events (see, e.g., Debayle and Kennett, 2000, Fishwick et al., 2005). This approach to surface-wave tomography relies on matching the waveforms on individual paths and then mapping of the path-specific constraints on shear structure into a 3$\mathrm{D}$ model. In contrast, higher frequency body wave arrivals are refracted back from the variations in structure in the mantle and are particularly sensitive to discontinuities in structure. Observations out to a distance of $3000 \mathrm{~km}$ provide coverage of the structures down through the lithosphere-asthenosphere boundary to the upper mantle transition zone below northern Australia (e.g. Kaiho \& Kennett, 2000). The combination of short-period and broadband observations has provided detailed information on both $\mathrm{P}$ and $\mathrm{S}$ wavespeeds and the variation in seismic wave attenuation with depth. Further information on 3-D variations in structure can be extracted from the patterns of travel-time residuals. The combination of these different types of information allows the main features of upper mantle structure to be characterised. There is a dramatic increase in seismic wave attenuation in the asthenosphere and thus such observations are important for mapping out the base of the lithosphere.

\section{Receiver functions}

Extensive use has been made of receiver function studies that exploit the conversions and reverberations that follow the onset of the seismic signal. These studies provide important information on crustal and uppermost mantle structure, particularly the depth and nature of discontinuities. The receiver function is constructed from the beginning of a seismogram by taking out the influence of the source; the resulting information on structure near the receiver can then be elucidated with careful modelling.

The receiver function studies provide an important supplement to the limited sampling available from refraction experiments and provide a full continental coverage. Initial work in eastern Australia by Shibutani et al. (1996) was extended by Clitheroe et al. (2000) to cover most of the continent, using portable broad-band stations and the limited number of highquality permanent stations at the time. A set of receiver function studies have been made of the West Australian cratons as detailed coverage has become available through portable broad-band deployments (see Reading et al., 2003, 2007, 2011).

Despite higher noise levels and more limited bandwidth, valuable receiver function controls on crustal thickness can be extracted from teleseismic records at higher frequencies. For example, stacking and waveform fitting, coupled to local surface-wave dispersion results, has been used to improve the spatial coverage of Moho depths in southeast Australia (Tkalčić et al, 2012).

\section{Body-wave tomography}

The initial application of mapping of the relative delay times of seismic arrivals was to investigate the major gravity anomalies in central Australia by using linear profiles of portable instruments (Lambeck et al., 1988). These studies revealed the need for substantial, but localised, variations in crustal thickness, to satisfactorily model the seismic results. The crustal thickness variations have since been corroborated by deep seismic reflection profiling across the Arunta Province and more recently across the Musgrave Province (Korsch \& Kositcin, 2010a). 
The arrival times of seismic phases from regional earthquakes at the various broad-band stations have been picked and used in a number of studies (e.g., Kaiho \& Kennett, 2000; Kennett \& Abdulah, 2011). The distribution of earthquakes means that detailed resolution using seismic waves refracted back from the mantle is confined to the northern part of Australia. Nevertheless these results provide independent corroboration of the presence of fast seismic wavespeed structure extending to $220 \mathrm{~km}$ or more beneath the cratons of central and western Australia.

High resolution work has been carried out in southeastern Australia using the dense networks of short-period stations that can be very clearly seen in Figure 1. Rawlinson et al. (2010) have combined refraction results from a marine survey around the island of Tasmania recorded at land stations with teleseismic data recorded at dense seismic arrays on the island. They have developed a high resolution P-wave tomographic model including a description of the crustmantle boundary, which is consistent with the limited results from deep reflection studies in Tasmania (e.g., Drummond et al., 2000).

\section{Lithospheric representation}

\section{Sediments}

Figure 3 displays the thickness of Neoproterozoic and Phanerozoic basins across Australia, building on input from reflection seismology, gravity and magnetic surveys (Frogtech 2005). We have used the results from full-crustal reflection profiling since 2004 to provide checks on the sediment thickness model. At the scale of AuSREM itself, the results are concordant, but there can be localised variations of a hundred meters or more.

In figure 3 we have employed the same $0.5 \times 0.5$ degree representation as for the other components of AUSREM, although some detail is lost, the gridded information provides a good representation at the continental scale. In Figure 3(a) we display the sedimentary thickness for Phanerozoic and Neoproterozoic basins and in Figure 3(b) add in the thickness of the older Proterozoic basins. Such older Proterozoic material is usually in the form of metasediments, and so will have seismic wavespeeds characteristic of basement.

Although a significant part of Australia is covered in sediments, the sequences on the continent are generally less than $7 \mathrm{~km}$ thick (Figure 3 ). Deeper basins ( $>15 \mathrm{~km}$ ) occur offshore particularly in northwestern Australia; they host most of Australia's oil and gas. Nevertheless the onshore basins are important with major coal deposits in eastern Australia, mostly from the Permian, and gas accumulations in the Cooper Basin in southern Queensland. The majority of these basins are associated with gentle downwarps associated with thermal sagging rather than localized rifting, and many in the western part of the continent lie on thick lithosphere.

Control on the seismic velocities of the sediments is rather patchy, and we hope that the availability of AuSREM will encourage the development of more detailed representations of the sedimentary sequences. 

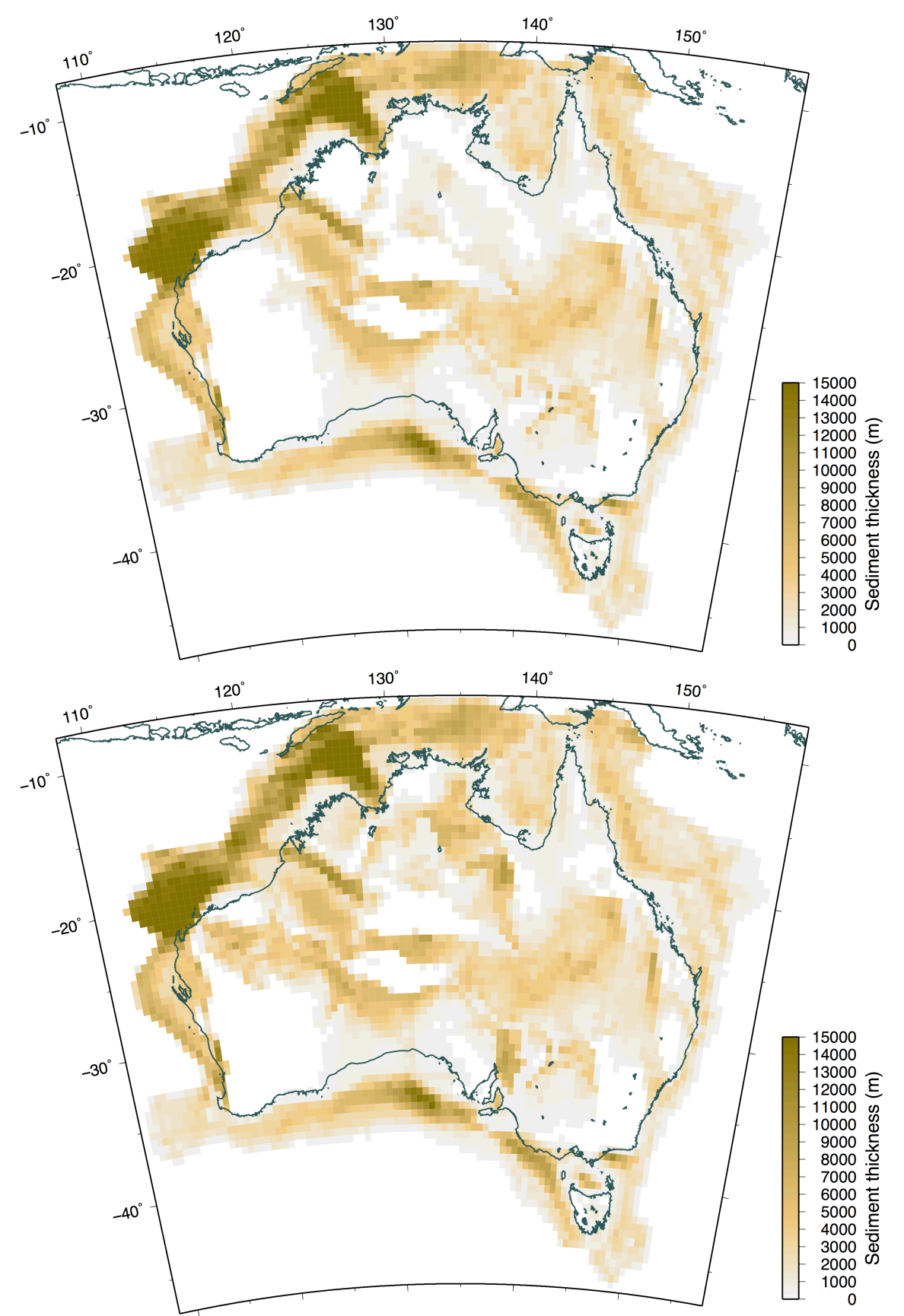

(b)

Figure 3- The distribution of Phanerozoic and Proterozoic sedimentary basin thickness across the continent based on the OZSeebase study (Frogtech, 2005) rendered onto the AuSREM 0.5x0.5 degree grid using pixels at the grid size. (a) Phanerozoic and Neoproterozoic basins, (b) with the inclusion of older Proterozoic basins.

\section{Shallow and Deeper Crust}

Information on the properties of the crust comes from refraction experiments that provide strong local constraints on $\mathrm{P}$ wavespeeds. Few such experiments have been carried out in recent years so the continental coverage is rather limited (see Figure 1 and the square symbols in Figures 4-6). Fortunately we are able to supplement with results from receiver function studies that are most sensitive to the presence of discontinuities, but which provide information on the $S$ wavespeed distribution through the crust. The information is specific to the receiver location, and sampling at the Moho generally extends to no more than $30 \mathrm{~km}$ 
from the seismic recorder. We use the receiver function results with lower weight than for refraction and this is indicated by the use of smaller diamond symbols in Figures 4-6.

Supplementary information is also available from the seismic tomography based on the analysis of ambient noise through the correlation of seismic records at pairs of stations. This approach (Saygin \& Kennett, 2010, 2012) emphasises the surface wave portion of the interstation response and we can extract the group velocity maps across the continent as a function of frequency. From the combination of multiple maps we can then infer the local shear wavespeed as a function of position. The resulting crustal structure provides a means of linking the results from the 'point' receiver functions to create a full 3-D structural representation.

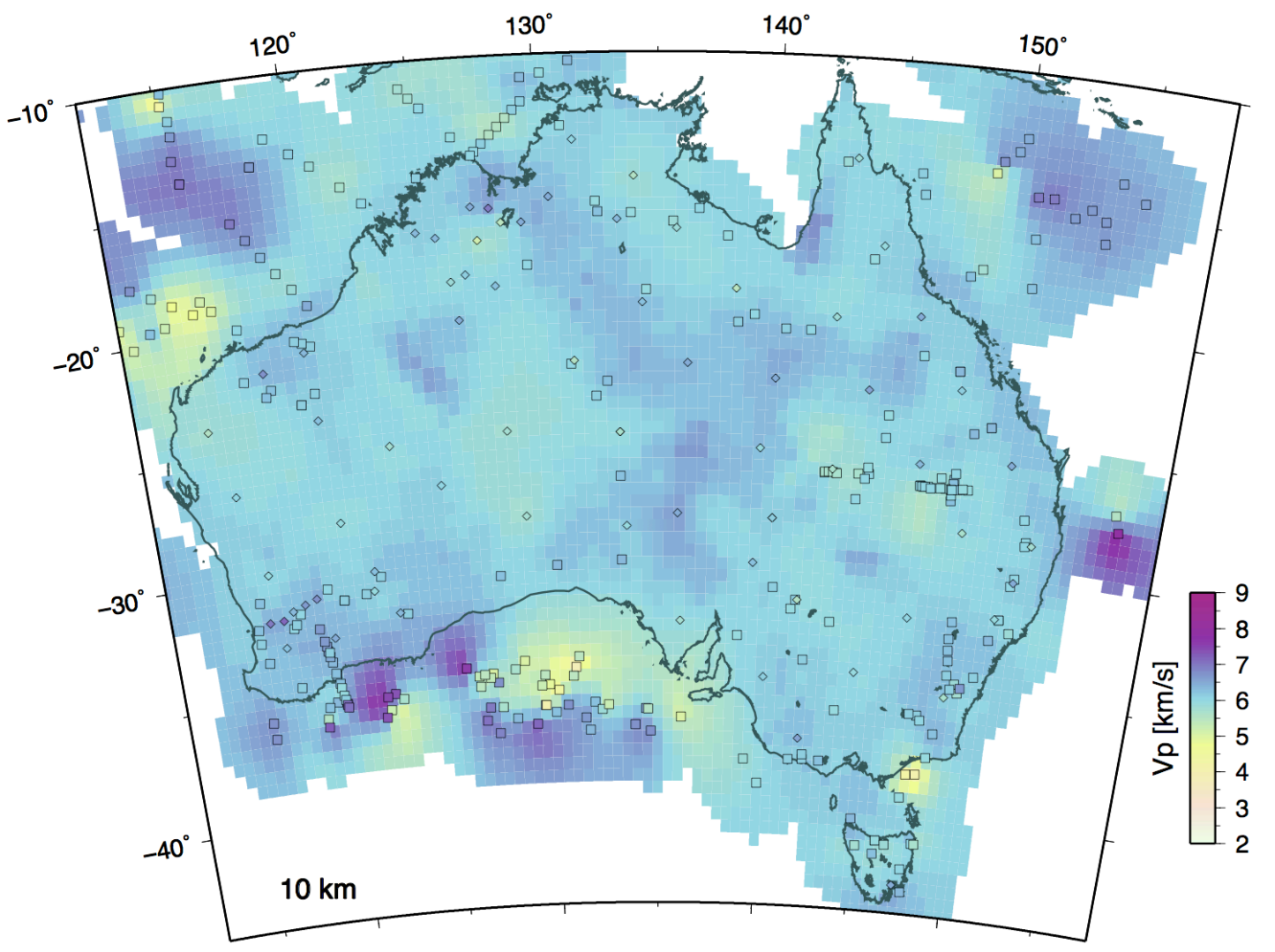

Figure 4: Map view of the $\mathrm{P}$ wavespeed distribution for the AuSREM crustal model (Salmon et al., 2012) in the shallow crust at $10 \mathrm{~km}$ depth. Constraints from refraction experiments are shown by squares and receiver functions by diamonds and are plotted using the same colour scale as for the crustal model.

Figures 4 and 5 show cross-sections through the $\mathrm{P}$ wavespeed distribution for the AuSREM crustal model (Salmon et al., 2012) at depths of 10 and $25 \mathrm{~km}$, and illustrate the level of wavespeed variability through the crust. The strongest variations at $10 \mathrm{~km}$ come from the presence of the thick sediments in the Great Australian Bight and the NorthWest Shelf. At this depth it is hard to discern the outlines of the main tectonic building blocks. By $25 \mathrm{~km}$ depth we encounter a shallow Moho in some offshore regions, but high crustal speeds are encountered in some portions of the central inland.

The primary information is on seismic wavespeeds and we need to provide conversions between $\mathrm{P}$ and $\mathrm{S}$ wavespeeds, and also to infer density profiles based on gravity observations (e.g. Aitken, 2010). We have used the results of receiver functions to build smooth models of 
the ratio between $\mathrm{P}$ and $\mathrm{S}$ wavespeeds, and then combined all the various classes of information including ambient noise tomography to construct compatible $\mathrm{P}$ and $\mathrm{S}$ wavespeed distributions (for further details see Salmon et al., 2012). We employ a relatively smooth variation in the $\mathrm{P} / \mathrm{S}$ wavespeed ratio to avoid issues arising from irregularity in data control. We have evidence for significant horizontal gradients in this wavespeed ratio, which are preserved, but we have not allowed for possible discontinuities in the ratio at terrane boundaries.

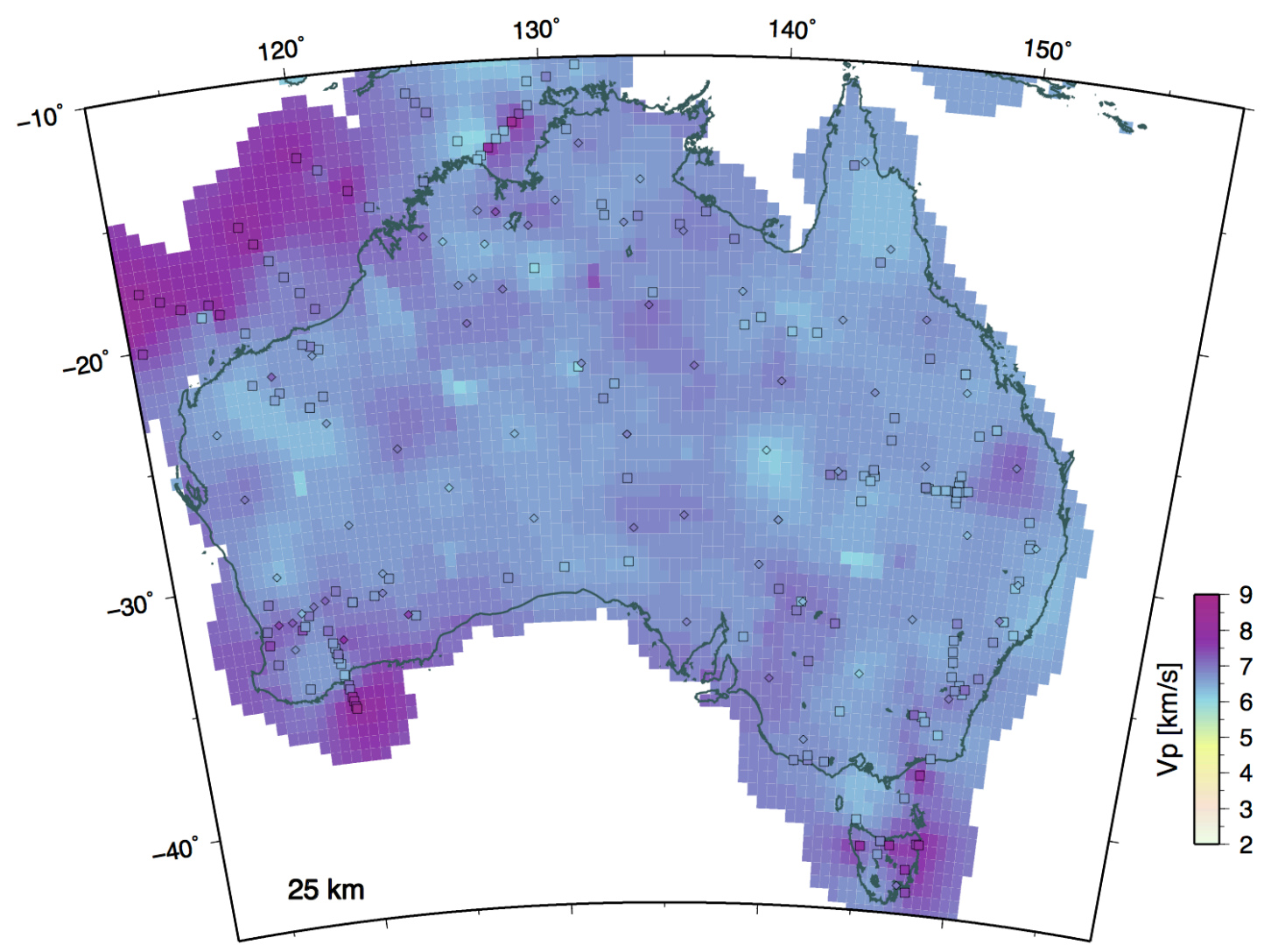

Figure 5: Map view of the P wavespeed distribution for the AuSREM crustal model (Salmon et al., 2012) in the deeper crust at $25 \mathrm{~km}$ depth. Constraints from refraction experiments are shown by squares and receiver functions by diamonds and are plotted using the same colour scale as for the crustal model.

Below $30 \mathrm{~km}$, a depth slice encounters both crustal material and the uppermost mantle in the areas with thinner crust. We show a map view at $40 \mathrm{~km}$ in Figure 6 and the areas with thicker crust become apparent by their lower P wavespeeds (cf. the Moho distribution in Figure 7). Velocity control is not as detailed as the depth control on the Moho, but there is generally good agreement between the different results. The symbols for the specific observations tend to blend into the background on Figure 7. 


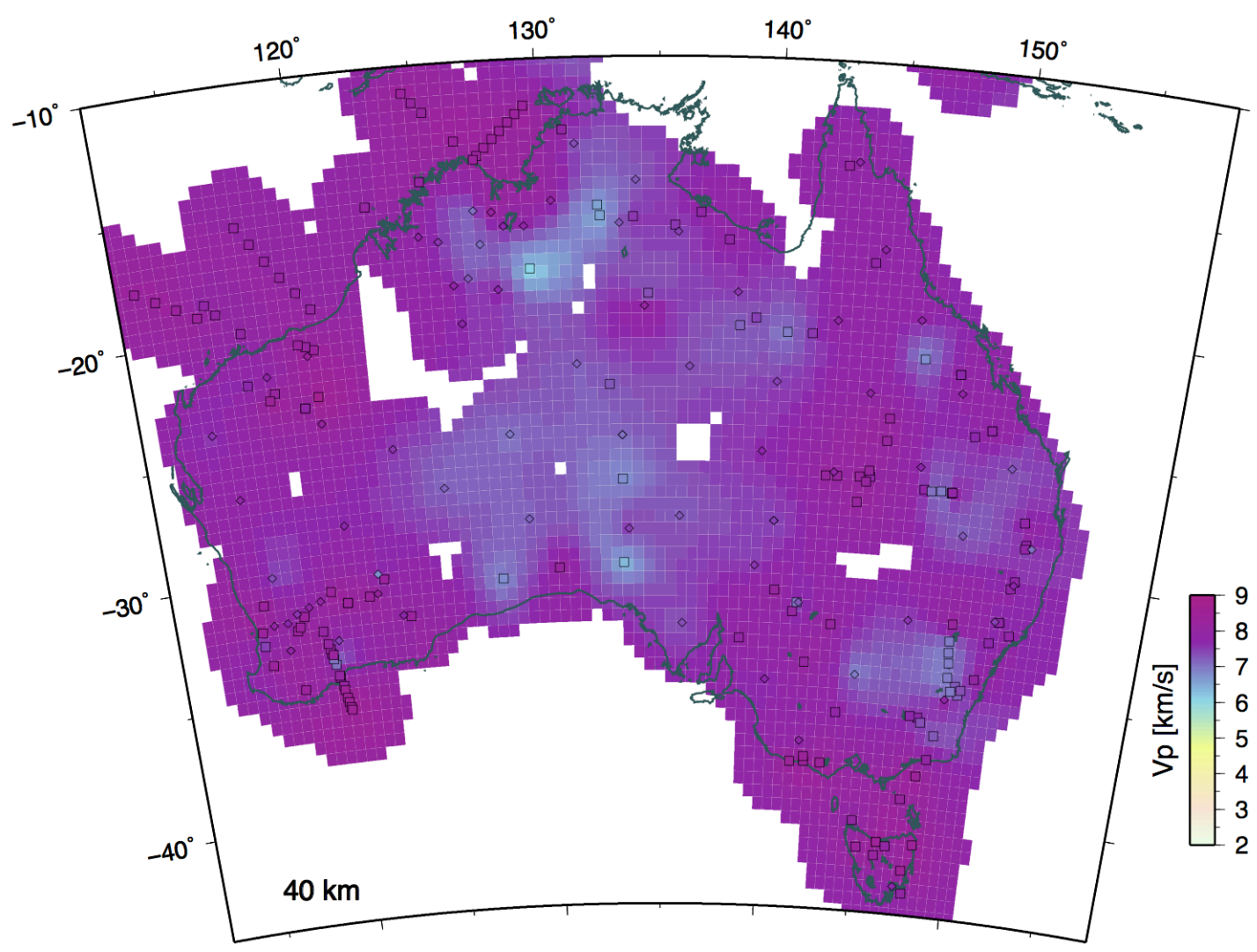

Figure 6: Map view of the P wavespeed distribution for the AuSREM crustal model (Salmon et al., 2012) at the base of the crust or in the uppermost mantle at $40 \mathrm{~km}$ depth. Areas with limited control are blanked out, but the crustal model is continuous. Constraints from refraction experiments are shown by squares and receiver functions by diamonds and are plotted using the same colour scale as for the crustal model.

\section{Crustal discontinuities}

We have conducted a thorough search of all the reflection lines and the interpreted wavespeed profiles from both refraction and receiver function studies to extract information on major discontinuities within the crust. There is no single coherent discontinuity across the continent within the crust, but prominent discontinuities are found at many levels (see Salmon et al., 2012). There is thus no simple division into distinct upper and lower crust.

There is some level of regional clustering in the estimates for discontinuity depths with, e.g., a consistent feature at around $24 \mathrm{~km}$ depth in southern Queensland (cf. Finlayson et al., 1984). On reflection profiles a sustained reflector can sometimes persist for $100 \mathrm{~km}$ or so before fading out. Some of the strongest and longest reflectors are seen in the Youanmi province of the northern Yilgarn craton, where they represent a clear separation between different styles of crustal reflectivity but have noticeable topography varying by more than $6 \mathrm{~km}$ in depth along a single recognisable interface.

\section{Moho}

One of the significant contributions made by the AuSREM project has been the construction of a new model for the depth to the Moho across Australia (Kennett et al., 2011). This model builds on the entire suite of available data from refraction, reflection and receiver function studies. The coverage is now very good across most of the continent (Figure 7), but there are still a number of remote desert areas with difficult access where sampling is rather sparse. The model in Figure 7 has been updated to include the results from 2012 reflection profiling in 
Western Australia, which have provided much improved controls on structures in the Albany-Fraser region.

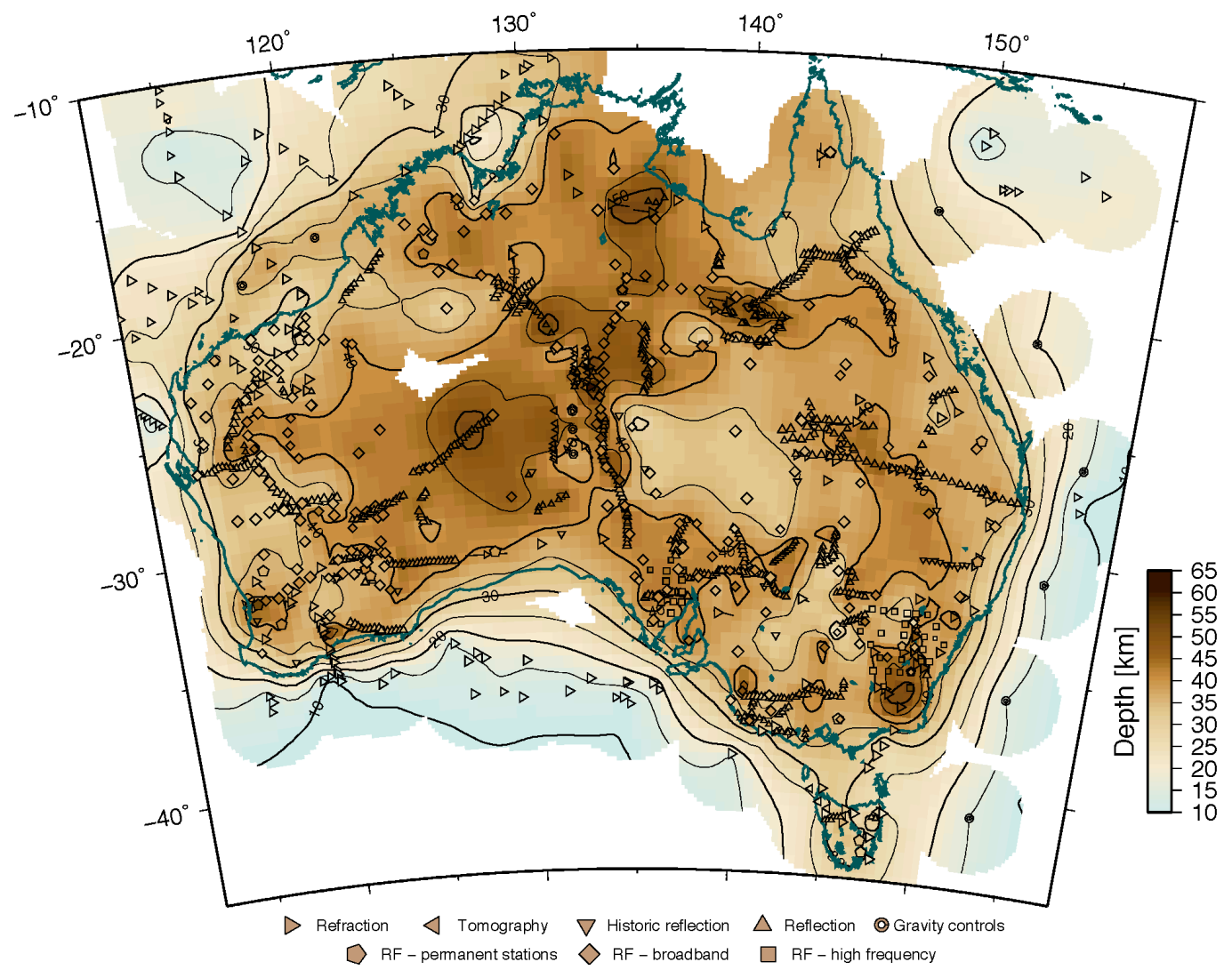

Figure 7: The depth to the Moho across Australia derived from a combination of seismic refraction, refraction and receiver function studies (updated from Kennett et al., 2011). The values obtained from different classes of observations are indicated by the colours attached to the distinctive symbols for each data type.

The inclusion of Moho picks at 20-40 km intervals taken from more than $12,000 \mathrm{~km}$ of reflection profiling has been particularly important in constraining the Moho map. Previously isolated seismic stations can now be linked, and also cross-checks provided on results from other methods. In general, the consistency between techniques is very high and in most places the variation in crustal thickness estimates are less than $3 \mathrm{~km}$. The thickest crust (more than $50 \mathrm{~km}$ thick) is mapped beneath the eastern highlands, central Australia and the Mt Isa region. The crust thins towards the continental edge, although it is still over $35 \mathrm{~km}$ thick in regions of the North West Shelf (Figure 6). The thinnest crust on the mainland is around $30 \mathrm{~km}$ or less in the northeast part of South Australia; a region with coincident high heat-flow anomalies (Neumann et al., 2000). The crust is also relatively thin under the Pilbara craton.

There is significant variation in the seismic character of the crust-mantle transition. The character varies from a very distinctive and sharp change in reflectivity that may extend laterally for hundreds of kilometres, to a more diffuse and difficult to identify boundary. A sharp Moho is particularly characteristic of the main cratonic regions of Archaean crust such as the Yilgarn (Goleby et al., 2002), but also regions of northeast Queensland with Proterozoic upper crust (Chopping \& Henson, 2009). The more diffuse character Moho occurs in 
Proterozoic crustal blocks, such as the Curnamona and eastern Gawler (Korsch \& Kositcin, 2010b), or northern Gawler to Arunta in central Australia (Korsch \& Kositcin, 2010a).

The reflection profiling results provide evidence for a number of sharp changes in crustal thickness, notably in central Australia (e.g., Goleby et al., 1989; Korsch \& Koscitin 2010a) where offsets may exceed $20 \mathrm{~km}$. The rate of change of crustal thickness can be rapid, with also small jumps apparently related to crustal sutures as in northern Queensland (Chopping \& Henson, 2009). Such features pose a challenge when we try to provide a suitable representation of the Moho surface (Figure 7). At the southern margin of the Capricorn orogen and at the contact of the Yilgarn craton with the Musgrave block, it appears that the Proterozoic domain is pushed under the craton to give a local doubling of the Moho. The range and diversity of localised features in the configuration of the Moho is consistent with such contrasts being sustained since their formation, in some cases around $1900 \mathrm{Ma}$.

\section{Lithospheric Mantle}

The seismological results reveal a complex pattern of 3-D structure beneath the Australian Plate. The dominant control on the seismic wavespeeds in the mantle is from temperature, with a decrease in velocity with increasing temperature. As a result the variations in the wavespeed with depth can be interpreted in terms of changes in lithospheric thickness. The cratonic region in the centre and west of Australia is underlain by a thick mantle lithosphere extending to over $200 \mathrm{~km}$ depth with fast wavespeeds (especially for shear waves). Beneath the eastern region of younger Phanerozoic upper crust, the lithosphere is generally thinner (less than $140 \mathrm{~km}$ ) and the asthenosphere has a pronounced low velocity zone for shear waves with high attenuation of shear wave energy.

The configuration of regional earthquakes around Australia has been extensively exploited in the analysis of multiply reflected shear waves and surface waves that form the most prominent part of seismograms. A variety of styles of seismic tomography have been employed to build 3-D maps of the shear wavespeed distribution beneath the whole continent (e.g., Debayle \& Kennett, 2000; Simons et al., 2002, Fishwick et al., 2005; Yoshizawa \& Kennett, 2004; Fichtner et al., 2009, 2010). As a result, structural variations have been imaged on horizontal scales down to $250 \mathrm{~km}$, and significant substructure is apparent within the zones of both elevated and lowered wavespeeds (Figure 8). The AuSREM mantle component is designed to be representative building on features from different models generated using surface wave tomography, with the incorporation of information from body wave studies (Kennett et al., 2012). The general consistency between the different models has meant that the major features of the structure are well defined and the differences are mostly in smaller scale features. The AUSREM mantle model allows for polaristaion anisotropy with separate models for SV waves (vertically polarised, related to Rayleigh surface waves) and SH waves (horizontally polarised related to Love surface waves). We have also constructed $\mathrm{P}$ wavespeed, density and attenuation distributions for the mantle, for details see Kennett et al. (2012). 


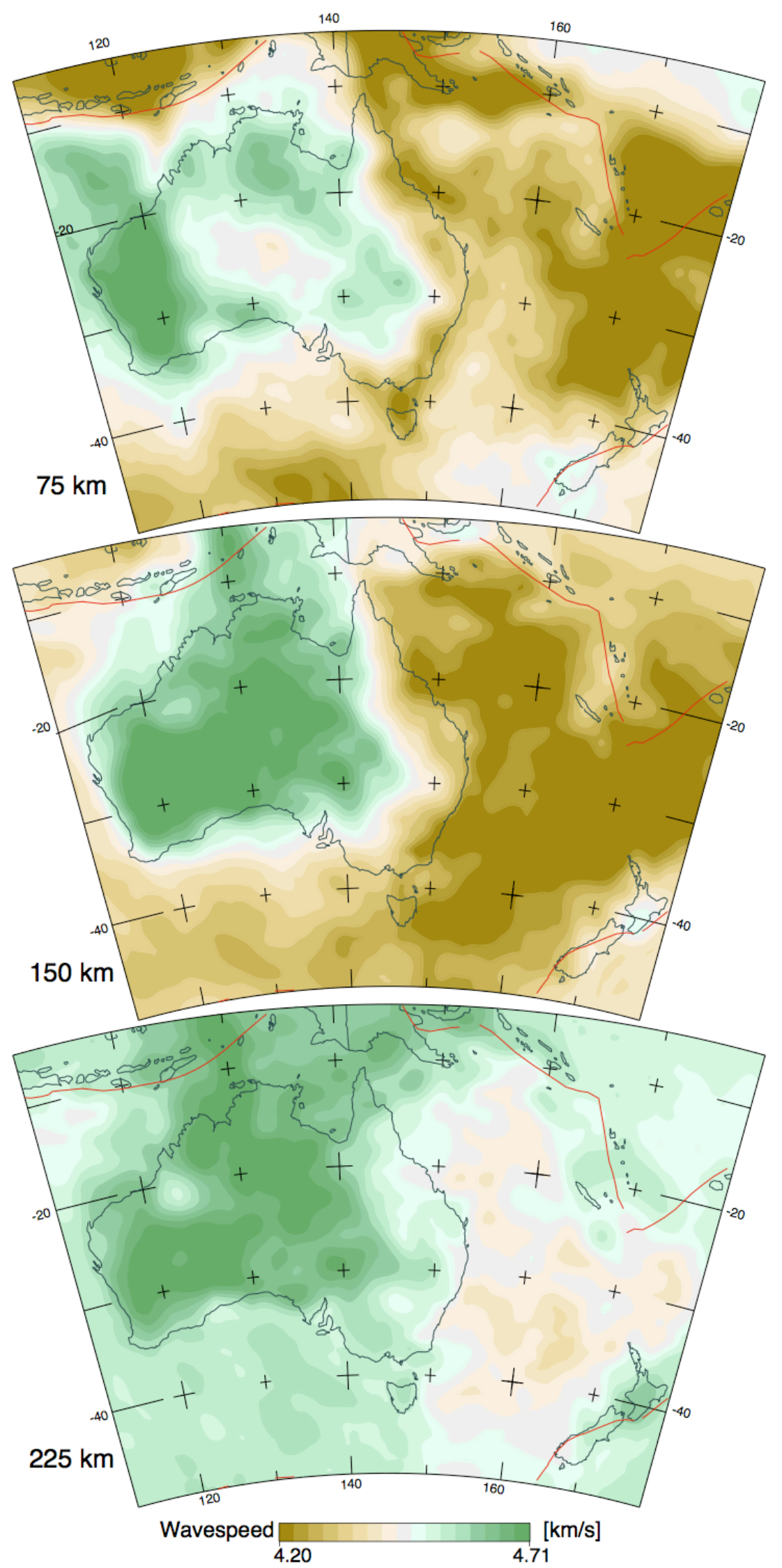

Figure 8: Representative lithospheric SV wavespeeds below the Australian region at a sequence of depths: (a) 75 $\mathrm{km}$ (b) $150 \mathrm{~km}$ (c) $225 \mathrm{~km}$ from the AuSREM mantle model (Kennett et al., 2012). 
The centre of Australia has relatively low wavespeeds at $75 \mathrm{~km}$, but there are strong gradients with depth, and by $125 \mathrm{~km}$ a broad zone of fast wavespeeds is established across the centre and west of Australia that persists to more than $200 \mathrm{~km}$ depth. In contrast in the Tasman Fold belt to the east, the seismic wavespeeds in the mantle are somewhat lower and the lithosphere is relatively thin, with estimates around $80 \mathrm{~km}$. The Tasman Sea region displays quite low shear wavespeeds (down to $4.2 \mathrm{~km} / \mathrm{s}$ ), probably as a result of residual heat left from failed rifting around $80 \mathrm{Ma}$. Fishwick et al. (2008) have presented evidence for the progressive eastward thinning of the lithosphere across Australia, which occurs as a series of discrete steps with quite sharp transitions. This result poses interesting questions as to how such lithospheric steps can be maintained over extended periods of geological time.

Goes et al. (2005) used the patterns of seismic wavespeeds determined from surface-wave tomography to extract information on the temperature in the mantle lithosphere beneath Australia. The mantle lithospheric temperature range is about $1000^{\circ} \mathrm{C}$, with a broad-scale correlation between temperature and tectonic age. Within each tectonic province there are, however, temperature differences ranging from $200^{\circ} \mathrm{C}$ to $700^{\circ} \mathrm{C}$. There are no significant differences in the temperatures beneath the Archaean and Proterozoic regions. In the east, the temperatures approach the moist solidus.

\section{Transition to the Asthenosphere}

The lithosphere beneath the older parts of the continent can be readily recognised by fast shear wavespeeds (up to $4.7 \mathrm{~km} / \mathrm{s}$ ), but the transition to the asthenosphere is not marked by any sharp transition. Rather there is a gradation from a conductive to a convective regime, most likely linked also to a change in rheology from dislocation to diffusion creep. The presence of the asthenosphere is manifest in enhanced seismic attenuation. The fast lithospheric wavespeeds are accompanied by little loss of seismic energy, enabling high frequency waves to propagate readily from subduction zones into continental Australia (Kennett \& Furumura, 2008). These high frequency waves are, however, suddenly lost when the seismic waves penetrate into the asthenosphere, because of its much higher attenuation of shear waves than in the lithosphere (Gudmundsson et al., 1994). Kennett \& Abdulah (2011) have used the full range of arrivals at portable stations across Australia to undertake attenuation tomography that confirms the presence of much stronger attenuation below 210 $\mathrm{km}$ depth.

In Figure 9 we show an estimate of the depth to the base of the lithosphere based on a variety of lines of evidence including the analysis of refracted waves in the mantle, the wavespeeds and gradients deduced from surface-wave tomography and body-wave tomography. The relative variations in the thickness of the lithosphere should be reliable and useful for geodynamic interpretation, but the absolute values depend on exactly where the boundary is drawn in a gradational transition. The contrast between thick lithosphere in the centre and west and thinner lithosphere in the east is very clear, and the nature of the transition is consistent with the analysis of Fishwick et al. (2008). The base of the lithosphere is somewhat irregular and this is likely to impose complex stress patterns from the relative motions of the thick continental lithosphere and the free-flowing asthenosphere. Farrington et al. (2010) have suggested that a southern edge to the cratonic lithosphere has produced edge induced convective flow associated with the northern motion of Australia at about $7 \mathrm{~cm} / \mathrm{yr}$ that is linked to the eruption of the Newer Volcanic Group in Victoria and South Australia, with the youngest event dated at $4.6 \mathrm{ka}$. 


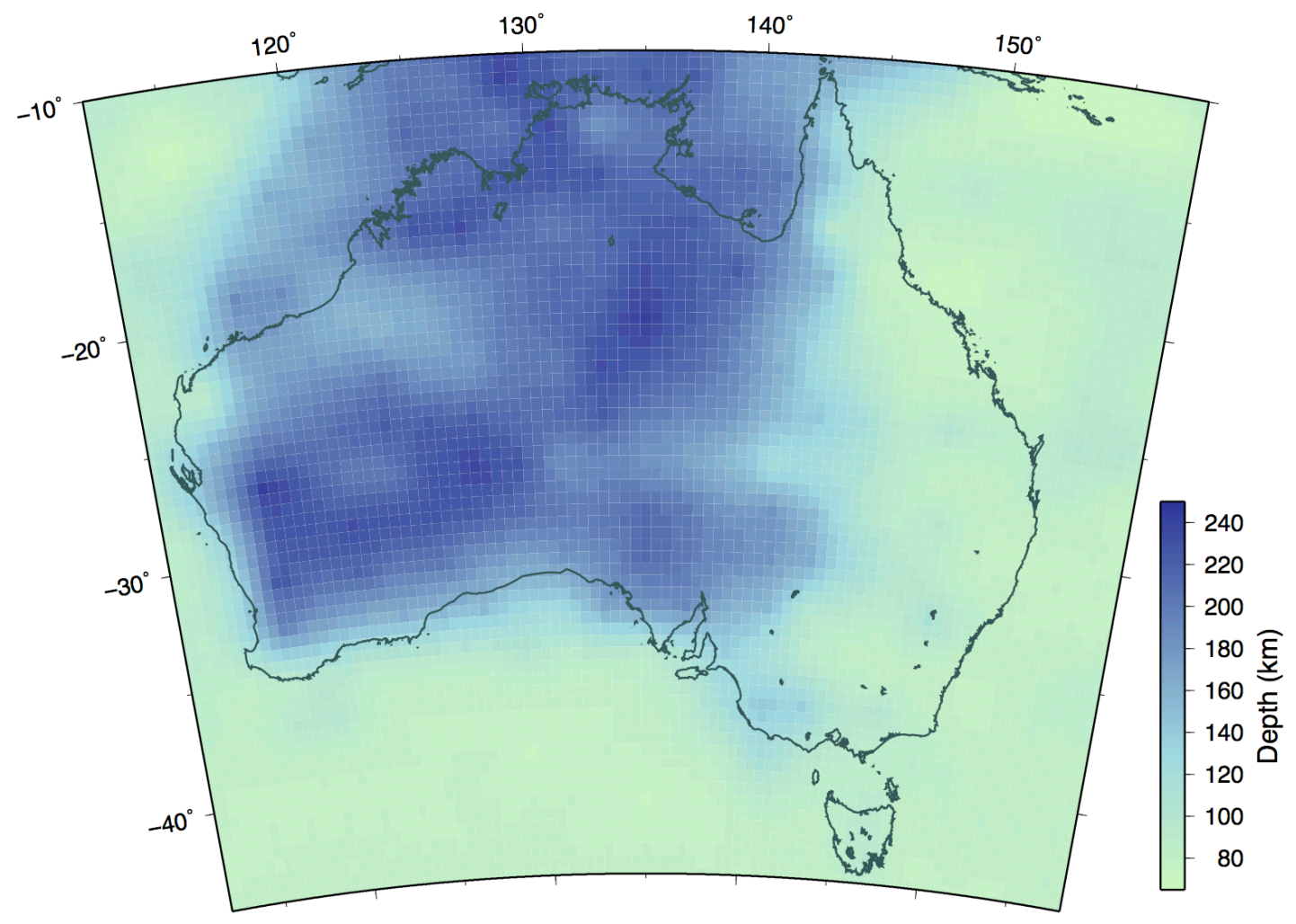

Figure 9: Estimate of the depth to the base of the lithosphere beneath Australia derived from a variety of seismological data, based on the AuSREM mantle model (Kennett et al., 2012)

\section{Discussion}

Thick subcontinental lithosphere is difficult to melt, but can be mechanically weakened by stretching. The way in which sedimentary basins evolve through time, from rifting to thermal subsidence is strongly influenced by the thickness and structure of the underlying lithosphere. Heat takes longer to conduct through thick lithosphere, so that the thermal sag sedimentation phase following rifting is delayed and prolonged. Australia's intracontinental basins are widespread, and were filled over a prolonged time interval, as a consequence of the thick lithosphere. Many of these basins, which are typically $<5 \mathrm{~km}$ thick, comprise several successor basins that range in age from $850 \mathrm{Ma}$ to the Pliocene.

The crustal thickness on the Australian continent ranges from nearly $60 \mathrm{~km}$ to $25 \mathrm{~km}$, with much of the crust having thickness between 38 and $42 \mathrm{~km}$ (Figure 7). The thickest crust occurs beneath the Palaeozoic in the east and in parts of central and northern Australia. Deep seismic reflection studies of the Australian Precambrian terranes support the concept of somewhat thickened Proterozoic crust compared to Archean crust, though there is no simple pattern of age progression (Aitken, 2010; Kennett et al., 2011). Drummond \& Collins (1986) suggested that lower crustal mafic underplating was the main process responsible for this thickening. Such a mechanism would be consistent with the progressive loss of crustal reflectivity seen in reflection profiling across the regions with thickest crust; since interleaved mantle material reduces contrasts in physical properties. However, the same episodes of upper 
mantle melting do not appear to have underplated the Archaean crust adjacent to the Proterozoic crust in the western part of the continent (Goncharov et al., 1998).

The crust is an integral component of the lithosphere and its thickness also controls the behaviour of the overall lithosphere to deformation (e.g., Behn et al., 2002). Thin crust results in deformation being localised into the mantle and so the width of any rift basin is controlled by the vertical geothermal gradient. Thick crust in contrast, allows stress accumulation in the crust to be greater than in the mantle, so rift basin width becomes dependent on both the vertical geothermal gradient and the rheology of the crust. Rifting tends to exploit former lines of weakness, but does not always succeed; Bass Strait represents a failed rift in the separation of Australia and Antarctica. This feature is linked to important sedimentary deposits with much of the known oil accumulations. The Centralian Superbasin dating from the Neoproterozoic is also located across the ancient sutures between northern and southern Australia.

Horizontal slices through the tomographic volume reveal additional complexity in Australia's deeper lithosphere. A zone of slower than average shear wavespeeds is imaged below the crust at around $75 \mathrm{~km}$ (Figure 7). This slow zone extends east-west across most of the continent and correlates broadly with the mobile belts that join the three cratonic elements of North Australia, South Australia and the West Australia (Huston et al., 2012). This zone also corresponds with the former extent of the Centralian Superbasin, which formed following rifting during the Neoproterozoic breakup of the supercontinent Rodinia at around $825 \mathrm{Ma}$ (Li et al., 1999). These same regions have also experienced intense and punctuated contractional deformation that in places has exhumed mid crustal rocks to the surface. The slow wavespeeds at $75 \mathrm{~km}$ depth revealed by seismic tomography are difficult to explain, and the suitable combination of thermal or compositional structure remains a question of considerable interest. For example, these slow wavespeed regions may have acted as, or continue today to act as, zones of lithospheric weakness. Such zones would favour the formation of sedimentary basins and mountain ranges and be the locus of seismicity.

Thick lithosphere also impacts on resources such as diamonds. Diamonds are formed at high pressures $(>150 \mathrm{~km})$ and generally require a thick lithosphere and low geothermal gradient to form and be preserved. Australia is major diamond producer, especially from the Argyle deposit in northwest Western Australia. Diamond deposits seem largely to be associated with the edges of zones of thickened lithosphere (O’Neill et al., 2005).

A recent compilation of Australia's neotectonic features by Clark et al. (2011) has suggested that the distribution of seismic activity is dependent on whether or not the crust has been extended. In their definition, crust without extension includes cratons, platforms and fold belts, whereas extended crust includes intracontinental rifts of all ages and passive margins no younger than $\sim 25 \mathrm{Ma}$. They suggest that regions of extended crust tended to be more seismically active. The age of major rifting appears to be important in terms of neotectonic activity level in extended crustal domains so that Palaeozoic intra-cratonic rifts and passive margins are less active than those rifted in the Mesozoic, with greater activity in northwestern than southeastern Australia.

The Flinders Ranges in South Australia are accommodating around one third of the seismic strain across the whole the continent, but do not fit into the general pattern of age relations. 
These ranges are actively uplifting, with thrust faults placing Precambrian rocks onto Quaternary rocks in places (Quigley et al., 2010). This zone of weakness arises from the orientation of the current maximum stress direction perpendicular to basin controlling faults, coupled with the elevated heat flow in the region (Neumann et al., 2000).

\section{Conclusions}

The AuSREM project provides a description of the major features of the Australian lithosphere both in the crust and the upper mantle. The structure is designed to be representative, and has been based on the combination of many different lines of evidence. The aim has been to provide a good representation of 3-D structure, which is useful for applications, yet is presented in a way that can be refined as extra information becomes available.

We have been able to combine information from refraction experiments, receiver function studies and ambient noise tomography to provide a full representation of the major variations of seismic wavespeeds in the crust across the continent, linked to inferred density profiles based on gravity observations (e.g. Aitken, 2010). The new synthesis provides a new summary of the Australian crust based on Australian-specific data.

The Moho, the major boundary in the upper lithosphere, is highly variable in its character and depth below the surface. Depths to Moho across the continent range from 29-60 km, despite an average elevation of only $\sim 330 \mathrm{~m}$ above sea level. There are rapid variations in crustal thickness in central Australia that give rise to major east-west oriented gravity anomalies. The character of the transition from crust to mantle is highly variable with extended gradients accompanying the deepest Moho, probably associated with mafic underplating. There is no simple relationship between depth to Moho and crustal age, though many of the zones of thickest crust are in regions of Proterozoic outcrop.

More than two thirds of the Australian continent is underlain by lithosphere over $200 \mathrm{~km}$ thick, which is more than double the global average for lithospheric thickness. This thick lithosphere underlies the Precambrian zones of western and central Australia and shows high seismic wavespeeds. The thinner lithosphere in the east beneath the Phanerozoic reflects the influence of the failed rifting of the Tasman Sea. The presence of thick lithosphere has controlled many features of Australian geology and geography; with a major influence on how the continent has responded to tectonic forces related to breakup and amalgamation. The contrasts in lithospheric thickness between the west and centre of the continent and the east provide controls on topography and landscape, seismicity, the evolution of sedimentary basins evolution, heat flow and other resources.

The full AuSREM model provides a representation of 3-D structure beneath Australia and its environs that can be used for many purposes. Both crustal and mantle components should be useful in gravity modelling and in studies of dynamic topography. AuSREM provides crustal corrections for surface wave tomography and delay time tomography on a finer scale. Tools are under active development for location of earthquakes in the full 3-D model, and for earthquake source characterisation. 


\section{The AuSREM Model}

The AuSREM model is presented in full at the web-site

\section{http://rses.anu.edu.au/seismology/AuSREM}

from which the model can be downloaded in a number of formats, and where it is also possible to generate maps and depth profiles.

$\mathrm{P}$ wavespeed, $\mathrm{S}$ wavespeed and density are provided for the crustal model. For the mantle both SV and SH wavespeeds are given, together with $\mathrm{P}$ wavespeed, density and $\mathrm{S}$ wave attenuation. The new Moho model is also included.

The web site also provides wavespeed information for the full set of refraction experiments and receiver function studies.

\section{Acknowledgements}

Many people have been involved with different aspects of the AuSREM work and in particular the model depends on the work of:

E. Saygin, N. Rawlinson, S. Pozgay, H. Tkalčić, E. Vanacore, The Australian National University;

C. Collins, B. Goleby, A. Goncharov, J. Maher, T. Fomin, Geoscience Australia;

A.M. Reading, University of Tasmania;

A. Aitken, S. Revets, University of Western Australia;

S. Fishwick, University of Leicester;

A. Fichtner, University of Utrecht;

K. Yoshizawa, Hokkaido University;

S. Klemme, University of Muenster;

T. Shibutani, Kyoto University;

G. Clitheroe, GNS, New Zealand;

P. Arroucau, North Carolina Central University;

F.R. Fontaine, Université de Reunion.

An extensive set of national databases are held at Geoscience Australia (http://www.ga.gov.au), which have been very valuable for the preparation of this article; much of these data are freely accessible. The programme of passive seismological studies has received considerable support from the Australian National University and, in recent years, from the Australian Research Council. We are grateful to the Geological Society of Western Australia for rapid access to recent reflection profiles.

The AuSREM project has been jointly supported by AuScope and the Research School of Earth Sciences, Australian National University. 


\section{References}

AITKEN A.R.A. 2010. Moho geometry gravity inversion experiment (MoGGIE): A refined model of the Australian Moho and its tectonic and isostatic implications. Earth and Planetary Science Letters 297, 71-83.

BeHN M.D., LiN J., \& ZUBER, M.T. 2002. A continuum mechanics model for normal faulting using a strain-rate softening rheology: implications for thermal and rheological controls on continental and oceanic rifting. Earth and Planetary Science Letters 202, 1-16.

Braun J., Dooley J., Goleby B., VAN Der Hilst R., \& KlootwiJK C., (EdS.) 1998. Structure and Evolution of the Australian Continent, American Geophysical Union Geodynamic Series 25, $186 \mathrm{pp}$.

Chopping R. \& Henson P.A. (EDs.) 2009. 3D map and supporting geophysical studies in the North Queensland region. Geoscience Australia Record 2009/29, 82 pp. http://www.ga.gov.au/image_cache/GA15585.pdf

Christensen N.I. \& MoOneY W.D., 1995. Seismic Velocity Structure and Composition of the Continental Crust: A Global View. Journal of Geophysical Research 100, 9761-9788.

Clark D., MCPherson A. \& Collins C.D.N. 2011. Australia's seismogenic neotectonic record: a case for heterogeneous intraplate deformation. Geoscience Australia Record 2011/11, 95 pp.

Clitheroe G., Gudmundsson O. \& Kennett B.L.N. 2000. The crustal thickness of Australia. Journal of Geophysical Research 105, 13697-13713.

DeBAyle E. \& KenNETT B.L.N. 2000. The Australian continental upper mantle - structure and deformation inferred from surface waves. Journal of Geophysical Research 105, 2544325540.

Debayle E., Kennett B. \& Priestley K. 2005. Global azimuthal seismic anisotropy: the unique plate-motion deformation of Australia. Nature 433, 509-512.

Direen, N.G. \& CRAWford, A J. 2003. The Tasman Line: where is it, what is it, and is it Australia's Rodinian breakup boundary? Australian Journal of Earth Sciences 50, 491-502.

Drummond B.J. (ED.) 1991. The Australian Lithosphere. Geological Society of Australia, Special Publication 17, 208 pp.

DRummond B.J. \& Collins C.D.N. 1986. Seismic evidence for underplating of the lower continental crust of Australia. Earth and Planetary Science Letters 79, 361-372.

Drummond B.J., Barton T.J., Korsch R.J., Rawlinson N., Yeates A.N., Collins, C.D.N., \& BROWN A.V. 2000. Evidence for crustal extension and inversion in eastern Tasmania, Australia, during the Neoproterozoic and Early Palaeozoic: Tectonophysics 329, 1-21.

Eaton D.W., Darbyshire P., Evans R.L., Grütter H., Jones A.G. \& Yuan X., 2009. The elusive lithosphere-asthenosphere boundary (LAB) beneath cratons. Lithos 109, 1-22.

FARrington R., STEGMAN D., MORESI L.N., SANDIFORD M., \& MAY D. 2010. Interactions of 3D mantle flow and continental lithosphere near passive margins. Tectonophysics 483, 20-28, doi:10.1016/j.tecto.2009.10.008

Fichtner A., Kennett B.L.N., Igel H. \& Bunge H.-P. 2009. Full seismic waveform tomography for upper-mantle structure in the Australasian region using adjoint methods. Geophysical Journal International 179, 1703-1725.

Fichtner A., KennetT B.L.N., Igel H. \& Bunge H.-P. 2010. Full seismic waveform tomography for radially anisotropic structure: New insights into the past and present states of the Australasian upper mantle. Earth and Planetary Science Letters 290, 270-280.

Finlayson, D.M., Collins, C.D.N. \& LOCK, J., 1984. P-wave velocity features of the lithosphere under the Eromanga Basin, eastern Australia, including a prominent midcrustal (Conrad?) discontinuity. Tectonophysics 101, 267-291. 
Finlayson, D.M., 2010. A Chronicle of Deep Seismic Profiling across the Australian Continent and its Margins, 1946-2006, D.M. Finlayson, Canberra, pp 255 (doug.finlayson@netspeed.com.au).

FisHWick S., KENNETT B.L.N. \& READING A.M. 2005. Contrasts in lithospheric structure within the Australian Craton. Earth and Planetary Science Letters 231, 163-176.

Fishwick S., Heintz M., Kennett B.L.N., Reading A.M. \& Yoshizawa K. 2008. Steps in lithospheric thickness within eastern Australia, evidence from surface wave tomography. Tectonics 27, TC0049, doi:10.129/2007TC002116.

Fouch M.J. \& Rondenay S. 2006. Seismic anisotropy beneath stable continental interiors. Physics of the Earth and Planetary Interiors 158, 292-320, doi:10.1016/j.pepi.2006.03.024

FrogteCh 2005. OZ SEEBASE ${ }^{\mathrm{m}}$ Study 2005, Public Domain Report to Shell Development Australia by FrOG Tech Pty Ltd.

Goes S., Simons F.J. \& Yoshizawa K. 2005. Seismic constraints on the temperature of the Australian uppermost mantle, Earth and Planetary Science Letters 236, 227-237, doi:10.1016/j.epsl.2005.05.001

Goleby B.R., Shaw R.S., Wright C., Kennett B.L.N. \& LAmbeck K. 1989, Geophysical evidence for 'thick-skinned' crustal deformation in central Australia: Nature, v. 337, pp. $325-330$.

Goncharov A.G., Lizinsky M.D., Collins C.D.N., Kalnin K.A., Fomin T.N., Drummond B.J., Goleby B.R. \& PlatonenKova L.N. 1998. Intra-Crustal "Seismic Isostasy" in the Baltic Shield and Australian Precambrian Cratons from Deep Seismic Profiles and the Kola Superdeep Bore Hole Data. In: Structure \& Evolution of the Australian Continent, Editors J. Braun et al., Geodynamics Series AGU 26, 119-138.

Graeber F.M., Houseman G.A. \& Greenhalgh S.A. 2002. Regional teleseismic tomography of the western Lachlan Orogen and the Newer Volcanic Province, southeast Australia. Geophysical Journal International 149, 249-266.

Gudmundsson O., KennetT B.L.N. \& Goody A. 1994. Broadband observations of upper mantle seismic phases in northern Australia and the attenuation structure in the upper mantle. Physics of the Earth and Planetary Interiors 84, 207-236.

Hillis R.R. \& MÜLlER R.D., (EDS.) 2003. Evolution and dynamics of the Australian Plate, Geological Society of Australia Special Publication 22 and Geological Society of America Special Paper 372, 432 pp.

Kaino Y. \& KenNetT B.L.N. 2000. Three-dimensional seismic structure beneath the Australasian region from refracted wave observations. Geophysical Journal International 142, 651-668.

Kennett B.L.N. \& AbDulah A. 2011. Seismic wave attenuation beneath the Australasian region. Australian Journal of Earth Sciences 58, 285-295.

KenNETT B.L.N. \& Furumura T. 2008. Stochastic waveguide in the Lithosphere: Indonesian subduction zone to Australian Craton, Geophysical Journal International, 172, 363-382.

Kennett B.L.N., SAlmon M., SAygin E. \& AusMoho Working Group, 2011, AusMoho: the variation of Moho depth in Australia. Geophysical Journal International 187, 946-958.

Kennett B.L.N., Fichtner A., Fishwick S. \& Yoshizawa K. 2012, Australian Seismological Reference Model (AUSREM): Mantle component. Geophysical Journal International, (submitted)

Korsch R.J. \& Kositcin N., (EDs.) 2010a. GOMA (Gawler Craton-Officer Basin-Musgrave Province-Amadeus Basin) Seismic and MT Workshop 2010. Geoscience Australia Record 2010/39, 162 pp. 
Korsch R.J. \& Kositcin N. (Eds.) 2010b. South Australian Seismic and MT Workshop 2010. Geoscience Australia Record 2010/10, 124 pp.

LeE C-T.A., Luffi P. \& ChIN E.J. 2011. Building and Destroying Continental Mantle. Annual Review of Earth and Planetary Sciences 39, 59-90.

MoOney W.D., LASKe G. \& MASTERS G., 1998. CRUST 5.1: A global crustal model at $5^{\circ} \times 5^{\circ}$. Journal of Geophysical Research 103, 727-747.

NEUmANn N., SANDIFORD M. \& FODEN J. 2000. Regional geochemistry and continental heat flow: implications for the origin of the South Australian heat flow anomaly. Earth Planetary Science Letters 183, 107-120.

O'NeILl CJ, Moresi L, \& Jaques A.L. 2005. Geodynamic controls on diamond deposits: implications for Australian occurrences. Tectonophysics 404, 217-236.

Quigley M.C., Clark D. \& SAndiford M. 2010. Tectonic geomorphology of Australia. Geological Society of London Special Publication 346, 243-265.

RaWlinson N., KenNetT B.L.N., VANACORE E., Glen R.A. \& FishWick S. 2011. The structure of the upper mantle beneath the Delamerian and Lachlan orogens from simultaneous inversion of multiple teleseismic datasets. Gondwana Research 19, 788-799.

Reading, A.M., KennetT, B.L.N. \& Dentith, M.C. 2003. The seismic structure of the Yilgarn Craton, Western Australia. Australian Journal of Earth Sciences 50, 427-438.

ReAding, A.M. \& KenNetT, B.L.N. 2003. Lithospheric structure of the Pilbara Craton, Capricorn Orogen and northern Yilgarn Craton, Western Australia, from teleseismic receiver functions. Australian Journal of Earth Sciences 50, 439-445.

READING A.M., KeNNETT B.L.N. \& GolEBY B.R. 2007. New constraints on the seismic structure of West Australia: Evidence for terrane stabilization prior to the assembly of an ancient continent? Geology 35, 379-382; doi: 10.1130/G23341A.1.

Reading, A.M., TkalČIĆ, H., Kennett, B.L.N., Johnson, S.P. \& Sheppard, S. 2011. Seismic structure of the crust and uppermost mantle of the Capricorn and Paterson Orogens and adjacent cratons, Western Australia, from passive seismic experiments, Precambrian Research, in press

Ritsema J., Deuss A., van Heijst H.J. \& Woodhouse J.H. 2011. S40RTS: a degree-40 shearvelocity model for the mantle from new Rayleigh wave dispersion, teleseismic traveltime and normal-mode splitting function measurements, Geophysical Journal International 184, $1223-1236$.

Salmon M.S., KennetT B.L.N. \& SAYgin E. 2012 Australian Seismological Reference Model (AUSREM): Crustal component, Geophysical Journal International (submitted)

SAYGIN E. \& KENNETT B.L.N. 2010. Ambient noise tomography for the Australian Continent. Tectonophysics 481, 116-125, doi:10.106/j.tecto.2008.11.013.

SAYGIN E. \& KenNETT B.L.N. 2012. Crustal structure of Australia from ambient seismic noise tomography. Journal of Geophysical Research, 117, B01304, doi:10.1029/2011JB008403.

ShibUtani T., SAmbridge M. \& KenNeTt B. 1996. Genetic algorithm inversion for receiver functions with application to crust and uppermost mantle structure beneath Eastern Australia, Geophysical Research Letters 23, 1829-1832.

Simons F.J., VAn DeR Hilst R.D., Montagner J.P., \& Zielhuis A. 2002. Multimode Rayleigh wave inversion for shear wave speed heterogeneity and azimuthal anisotropy of the Australian upper mantle. Geophysical Journal International 151, 738-754.

Tkalčić H., Rawlinson N., Arroucau P., Kumar A. \& KennetT B.L.N. 2012. Multi-step modelling of receiver-based seismic and ambient noise data from WOMBAT array: crustal structure beneath southeast Australia, Geophysical Journal International 188, 1681-1700 
Tong C., Gudmundsson O. \& KennetT B.L.N. 1994. Shear wave splitting in refracted waves returned from the upper-mantle transition zone beneath Northern Australia. Journal of Geophysical Research 99, 15783-15797.

VAN DER Hilst R., KenNeTt B.L.N., Christie D. \& Grant J. 1994. Project SKIPPY explores the lithosphere and mantle beneath Australia. EOS Transactions AGU 75, 177.

VAN DER Hilst R.D., KenNeTt B.L.N. \& ShibUTANi T. 1998. Upper mantle structure beneath Australia from portable array deployments, 39-58, in The Structure and Evolution of the Australian Lithosphere, Geodynamics Monograph 26, ed J. Braun et al, American Geophysical Union.

YoshizAWA K. \& KenNETT B.L.N. 2004. Multi-mode surface wave tomography for the Australian region using a 3-stage approach incorporating finite frequency effects. Journal of Geophysical Research 109, B02310; doi: 10.129/2002JB002254.

Young, M.K., Rawlinson N., Arroucau P., Reading A.M. \& H. TKalčić, (2011), Highfrequency ambient noise tomography of southeast Australia: New constraints on Tasmania's tectonic past, Geophys. Res. Lett., 38, L13313, doi:10.1029/2011GL047971. 